\title{
Association between blood glucose levels in insulin therapy and Glasgow Outcome Score in patients with traumatic brain injury: secondary analysis of a randomized trial
}

\section{Tao Yuan}

Department of Neurosurgery, the affiliated Lianyungang Oriental Hospital of Xuzhou Medical University Hongyu He

Department of Neurosurgery, the affiliated Lianyungang Oriental Hospital of Xuzhou Medical University Yuepeng Liu

Center for clinical research and translational medicine, the affiliated Lianyungang Oriental Hospital of Xuzhou Medical University

Jianwei Wang

Department of Neurosurgery, the affiliated Lianyungang Oriental Hospital of Xuzhou Medical University

\section{Xin Kang}

Department of Neurosurgery, the affiliated Lianyungang Oriental Hospital of Xuzhou Medical University

\section{Guanghui Fu}

Department of Neurosurgery, the affiliated Lianyungang Oriental Hospital of Xuzhou Medical University

\section{Fangfang Xie}

Department of Neurosurgery, the affiliated Lianyungang Oriental Hospital of Xuzhou Medical University

Aimin Li

Lianyungang No 1 People's Hospital

\section{Jun Chen}

Lianyungang No 1 People's Hospital

Wen-xue Wang ( $\nabla 60020210075 @ x z h m u . e d u . c n)$

Department of Neurosurgery,the affiliated Lianyungang Oriental Hospital of Xuzhou Medical University https://orcid.org/0000-0002-9865-6811

\section{Research Article}

Keywords: Traumatic brain injuries, Glasgow Outcome Score, hyperglycaemia, insulin therapy

Posted Date: June 14th, 2021

DOl: https://doi.org/10.21203/rs.3.rs-615839/v1 
License: (c) (i) This work is licensed under a Creative Commons Attribution 4.0 International License. Read Full License 


\section{Abstract}

Background: Too high or low blood glucose levels after traumatic brain injury (TBI) negatively affect the prognosis of patients with TBI. This study aimed to examine the relationship between different levels of blood glucose in insulin therapy and Glasgow Outcome Score (GOS) in patients with TBI.

Methods: This study was based on a randomized, dual-center, open-label clinical trial. A total of 208 patients who participated in the randomized controlled trial were followed up for 5 years. The information on disease, lab examination, insulin therapy, and operation of patients with TBI was collected. Also, the data on 5-year and 6-month GOS were collected as primary and secondary outcomes. The univariate analysis was used to detect variables that might contribute to outcomes, while the multivariate regression analysis was used to reveal the independent relationship between insulin therapy and outcomes. A generalized additive model (GAM) was used to investigate dose-response relationships between blood glucose levels and GOS. The results were presented as odds ratios (ORs) with their $95 \%$ confidence intervals $(95 \% \mathrm{Cls})$. We further applied a two-piecewise linear regression model to examine the threshold effect of blood glucose level and GOS.

Results: A total of 182 patients were involved in the final analysis. Compared with the non-intensive insulin therapy group, the 5-year GOS in the moderate-control intensive insulin therapy (IIT) group and the slight-control IIT group was 1.45 and 1.39 higher, respectively (both $P<0.05$ ); the 5-year GOS in the strictcontrol IIT group was 0.23 higher $(P>0.05)$. GAM revealed that a bell-shaped relationship existed between blood glucose levels in insulin therapy and 5-year or 6-month GOS. The inflection points of the mean blood glucose level were 6.73 and $8.97 \mathrm{mmol} / \mathrm{L}$ considering 5-year GOS as the outcome and were 6.95 and $8.88 \mathrm{mmol} / \mathrm{L}$ considering 6-month GOS as the outcome. The multivariate analysis showed that the 5-year GOS in the medium-level group ( $\geq 6.73$ and $<8.97 \mathrm{mmol} / \mathrm{L}$ ) increased by 0.83 [95\% confidence interval (Cl): 0.22-1.47] compared with that in the low-level group ( $<6.73 \mathrm{mmol} / \mathrm{L})$. Also, the 5 -year GOS in the medium-level group increased by 0.57 (95\% Cl: 0.02-1.08) compared with that in the high-level group $(\geq 8.97 \mathrm{mmol} / \mathrm{L})$.

Conclusion: A proper blood glucose range in insulin therapy could improve the outcomes of patients with $\mathrm{TBl}$; the range was $6.73-8.97 \mathrm{mmol} / \mathrm{L}$ according to our limited analysis.

Clinical Trial Registration: ClinicalTrials.gov, NCT02161055. Registered 11 Jun 2014.

\section{Introduction}

Traumatic brain injury (TBI) leads to death and disability in patients with trauma. Secondary brain injury affects the prognosis of patients with TBI significantly, while hyperglycemia is one of the important factors inducing secondary brain injury [1]. Recent studies confirmed that hyperglycemia could aggravate the damage of nerve function [2]. Acute hyperglycaemia following TBI, which is defined as the blood glucose level beyond $200 \mathrm{mg} / \mathrm{dL}(11 \mathrm{mmol} / \mathrm{L})$ during the early phase of injury, is a common symptom in patients with severe TBI $[3,4]$. Acute hyperglycaemia following TBI was supposed to be a physiological 
reaction, which was essential to support the high metabolism in the brain after TBI [3, 5]. However, acute hyperglycaemia was also reported to adversely affect the outcomes of patients with TBI $[4,6]$ through exacerbating the secondary injury [7]. Since maximum clinical observations agreed on the existence of a close relationship between acute hyperglycaemia and poor outcomes of patients with TBI [4, 6-10], early care of acute hyperglycaemia after TBI was clinically recommended [11]. However, in clinical practice, hypoglycaemia, which results from excess blood glucose control, was also found to adversely affect the outcomes of patients with TBI [12].

Too high or low blood glucose levels after TBI negatively affect the prognosis of patients with TBI [13, 14]. Therefore, the control of the blood glucose level in patients becomes an urgent problem directly related to the prognosis. Therefore, it has been hypothesized that adequate control of acute hyperglycaemia was necessary for patients' benefits [11, 12]. A previous randomized controlled trial (RCT) confirmed the aforementioned hypothesis; 7-13 mmol/L was recommended as the target blood glucose range in insulin therapy. This study used advanced data-analysis tools to confirm our previous findings and further narrow the target blood glucose range to direct the clinical practice.

\section{Methods}

\section{Patients}

The RCT was registered in ClinicalTrials.gov (NCT02161055) on June 5, 2014, before patient recruitment, which started in June 2014 and ended in December 2015. This was a randomized, parallel-assignment, open-label, controlled clinical trial conducted at the Affiliated Lianyungang Oriental Hospital of Xuzhou Medical University and Lianyungang No.1 People's Hospital, China. The protocol followed the Declaration of Helsinki and was approved by the Lianyungang Oriental Hospital Medical Ethics Committee and the Medical Ethics Committee of Lianyungang No.1 People's Hospital, China. According to the Standards of Medical Care in Diabetes [15], hyperglycemia was defined as rapid blood glucose $>7 \mathrm{mmol} / \mathrm{L}$ (126 $\mathrm{mg} / \mathrm{dL}$ ). Eligible patients with hyperglycemia after severe TBI were randomly assigned to either the intensive insulin therapy (IIT) group or the non-IIT group in the ratio of 3:1. The IIT group was further subdivided into three subgroups based on the target blood glucose level: $4.4-7.0 \mathrm{mmol} / \mathrm{L}$ (strict-control group), 7.1-10.0 mmol/L (moderate-control group), and 10.1-13.0 mmol/L (slight-control group). Computerized randomization was accomplished by investigators who could not contact the participants directly. Patients, outcome assessors, and statisticians were blinded to the information regarding grouping. If the eligible patients consented to the trial, sealed opaque envelopes with a randomly assigned serial number containing the accepted treatment programs were opened. The patients then underwent the corresponding treatment measures. In the case of any error or disclosure about randomization, a new randomization sequence was generated starting from the problematic serial number and applied to subsequent patients.

\section{Inclusion and exclusion criteria}


The inclusion criteria were as follows: (1) clinical diagnosis of severe closed TBI [16]; (2) Computed Tomography (CT) confirmation of severe closed TBI; (3) severe TBI following the indications for craniotomy; (4) blood glucose levels of $>7.0 \mathrm{mmol} / \mathrm{L}$ measured twice by rapid examination within $2 \mathrm{~h}$ after admission; (5) Glasgow Coma Score (GCS) of 3-8; (6) age 18-80 years; and (7) no history of diabetes mellitus. The exclusion criteria were as follows: (1) patients with multiple physical injuries; (2) patients with diabetic nephropathy with hemodialysis dependence; (3) patients with neurological disorders before craniocerebral trauma; (4) patients with a history of diabetes before craniocerebral trauma; (5) bilaterally dilated pupils; and (6) refusal of patient's relatives. Moreover, patients could withdraw from the trial under the following conditions: (1) discontinuation of the trial was necessary from a medical point of view, or (2) a request was received from the patient's family to stop the trial.

\section{Blood glucose control in insulin therapy}

Within the first week of hospitalization, rapid blood glucose levels were recorded once every $2 \mathrm{~h}$ in each group. Blood glucose measurement: Capillary blood was obtained from the tip of the ring finger to measure the blood glucose level. The blood should be collected from the same finger to ensure an accurate measurement. For measuring the blood glucose level of a patient undergoing transfusion, the blood should be collected from the tip of the finger of the limb without transfusion to ensure the accuracy of measurement.

In the IIT group, the blood glucose levels were monitored and controlled according to the Yale Insulin Infusion Protocol [17]. According to the Yale Insulin Infusion Protocol, the amount of insulin $(U)=$ [fasting blood glucose $(\mathrm{mmol} / \mathrm{L}) \times 18-100] \times 10 \times$ body weight $(\mathrm{kg}) \times 0.6 /(1000 \times 2)$. The insulin for injection $(400 \mathrm{U} / 10 \mathrm{~mL})$ was obtained from Wan-bang Biochemical Pharmaceutical Co., Ltd., China (Lot \# 1307230,1302225 , and 1307210). Insulin was infused into the vein at a rate of $0.1 \mathrm{U} /(\mathrm{kg} \times \mathrm{h})$ using a micropump. During this period, the blood glucose level was monitored once every $2 \mathrm{~h}$, and the insulin dose was adjusted accordingly. If the blood glucose level was higher than the target value, the insulin dose was gradually increased by $1-2 \mathrm{U} / \mathrm{h}$. When the blood glucose level reached the target value, the insulin dose was gradually decreased until its administration was terminated.

On the contrary, in the non-IIT group, the rapid blood glucose level measurement was performed once every $2 \mathrm{~h}$. When the blood glucose level was $\leq 13.0 \mathrm{mmol} / \mathrm{L}$, no intervention was performed. In the case of blood glucose level $>13.0 \mathrm{mmol} / \mathrm{L}$, insulin was subcutaneously injected regularly. Insulin was administered once every $8 \mathrm{~h}$ in a fasting state, whereas during venous or enteral nutrition infusion, it was infused $30 \mathrm{~min}$ before the nutrition infusion. When the blood glucose level reached $\leq 13.0 \mathrm{mmol} / \mathrm{L}$, the insulin infusion was terminated.

\section{Measurement of dependent variables}

During the original RCT, patients were treated using the following uniform protocol. (1) According to the Guidelines for the management of severe TBI [18], craniotomy for TBI was performed to mainly decompress and remove the hematomas. (2) During the operation, all patients underwent a ventricular 
puncture. The cerebrospinal fluid (CSF) was collected for biochemical analysis and cell culture. (3) All patients were closely monitored in the intensive care unit (ICU) of the Department of Neurosurgery. (4) Therapeutic protocols for severe traumatic brain injury were used. (5) Glucocorticoids, which could cause disorders of glucose metabolism, were not applied regularly in either of the groups. (6) During intravenous injection, glucose and insulin were mixed in a ratio of $5 \mathrm{~g}$ (glucose): $1 \mathrm{U}$ (insulin) to minimize the effects of exogenous glucose on the blood glucose level. When the patients finished the RCT, routine rehabilitation and daily life training were organized for them. The blood glucose, serum insulin, and blood glycosylated hemoglobin levels, as well as the CSF level of glucose, lactic acid, and chloride, were monitored. CSF was collected during surgery and obtained 1 week after surgery by lumbar puncture. GCS was used to evaluate the severity of the patient's condition, and a recording sheet was used to assess the patient's condition at hospital admission. The Acute Physiology and Chronic Health Evaluation II (APCHE II) score was recorded on each subsequent day in the ICU.

\section{Outcome measurement}

The outcome of the study was 5-year Glasgow Outcome Score (GOS). In supplementary analyses, we also analyzed the 6-month GOS. GOS definitions were as follows: 1, death; 2, persistent vegetative state; 3 , severe disability (conscious but disabled), needing daily support; 4, moderate disability (disabled but independent); 5, good recovery, normal active life with minimal deficits.

\section{Statistical analysis}

Continuous variables that conformed to normal distribution were described as mean (SD), while those not conforming to normal distribution were described as median (Q1-Q3). Categorical data were presented as numbers and percentages. The univariate analysis was used to scan variables that might contribute to outcomes, while the multivariate regression analysis was used to reveal the independent relationship between insulin therapy and outcomes. A generalized additive model (GAM) was used to investigate dose-response relationships between blood glucose levels and GOS. A linear regression model was employed to estimate the association between blood glucose levels and GOS. The results were presented as $\beta$ with their $95 \%$ confidence intervals ( $95 \% \mathrm{Cls}$ ). We selected these confounders based on statistical significance $(P<0.05)$ [19]. Adjustments were made for the following potential confounders: pupil changes; GCS before surgery; and APCHE II score.

We further applied a two-piecewise linear regression model to examine the threshold effect of blood glucose levels and GOS. The turning point for blood glucose level was determined using exploratory analyses, which involved moving the trial turning point along with the pre-defined interval and picking up the point that gave the maximum model likelihood. We also conducted a log-likelihood ratio test comparing the one-line linear regression model with the two-piecewise linear model, as described in previous analyses $[20,21]$.

Dummy variables were used to indicate missing covariate values, which was performed when more than $1 \%$ of continuous variables were missing. The two-sided alpha level was set at 0.05 . All the statistical 
analyses were performed using the Empower Stats (www.empowerstats.com, X\&Y solutions, Inc., MA, USA) and R software version 3.6.1 (http://www.r-project.org).

\section{Results}

\section{Characteristics of the patients}

A total of 208 participants who participated in the RCT were enrolled in this cohort and followed up to December 2020. Of the total participants, 26 cases were lost to follow-up, and 182 patients were involved in the final analysis (Fig. 1). For 182 patients, the median of age was 50 (34-59) years, the mean GOS before surgery was 5.46 (1.51) years, the mean APCHE II score before surgery was 28.73 (2.40), the mean blood glucose level before surgery was $19.08(2.25) \mathrm{mmol} / \mathrm{L}$, the mean glycosylated hemoglobin level during surgery was $5.83(0.96)$, the mean CSF glucose level during surgery was $5.26(0.81) \mathrm{mmol} / \mathrm{L}$, the mean CSF lactic acid level during surgery was $4.06(0.67) \mathrm{mmol} / \mathrm{L}$, the average blood glucose level in 7 days in insulin therapy was $9.05(2.68) \mathrm{mmol} / \mathrm{L}$, the median 6-month GOS was 3 (2-4) years, and the median 5-year GOS was 4 (1-4) years. Among these patients, 147 were men and 114 had pupil change (Tables 1 and 2).

\section{Difference in 5-year and 6-month GOS between insulin therapy groups}

When the non-IIT group with a high mean blood glucose range $(12.44 \pm 1.61 \mathrm{mmol} / \mathrm{L})$ was used as a reference, the sight-control IIT group exhibited 1.15 (95\% Cl: 0.56-1.74) higher 5-year GOS and 0.94 (95\% Cl: $0.41-1.47)$ higher 6-month GOS. Similarly, the moderate-control IIT group exhibited 1.26 (95\% Cl: 0.69-1.84) higher 5-year GOS and 1.01 (95\% Cl: 0.49-1.52) higher 6-month GOS, while the strict-control IIT group showed a statistically significant difference in both 5-year and 6-month GOS (Table 4). Combining slight-control (7.1-10 mmol/L) and moderate-control (10.1-13 mmol/L) IIT groups, we achieved a blood glucose range of 7.1-13 mmol/L, which positively affected the 5-year and 6-month GOS.

\section{Relationships between blood glucose levels and GOS}

A threshold, nonlinear association between the average blood glucose level in insulin therapy $(\mathrm{mmol} / \mathrm{L})$ and 5-years GOS was found in GAM. The solid red line represented the smooth curve fit between variables. Blue bands represented the $95 \%$ confidence interval from the fit. "Bell"-shaped relationships were found to exist between the average blood glucose level in insulin therapy and 5-year GOS (Fig. 2), in which 6.73 and $8.97 \mathrm{mmol} / \mathrm{L}$ (average blood glucose level) were identified as inflection points (Table 5). A similar curve was found between the average blood glucose level in insulin therapy and 6-month GOS (Fig. 2), in which 6.95 and $8.88 \mathrm{mmol} / \mathrm{L}$ (blood glucose level) were the inflection points (Table 5).

\section{Multivariate analysis between the average blood glucose level and 5-year GOS}

According to the inflection points about 5-year GOS, the average blood glucose level in IIT was assorted into three groups: low-level $(<6.73 \mathrm{~mol} / \mathrm{L})$, medium-level $\left({ }^{3} 6.73,<8.97 \mathrm{mmol} / \mathrm{L}\right)$, and high-level $\left({ }^{3} 8.97\right.$ 
$\mathrm{mmol} / \mathrm{L}$ ), which then was involved in multivariate regression analysis. The multivariate analysis showed that the 5-year GOS increased by 0.83 (95\% Cl: 0.22-1.43) in the medium-level group compared with the low-level group; also, the 5 -year GOS in the medium-level group also increased by 0.57 compared with that in the high-level group (95\% Cl: 0.05-1.08) (Table 6).

\section{Discussion}

Insulin therapy was used to clinically control the dramatic increase in the blood glucose level following $\mathrm{TBI}$ and benefit the outcomes of patients with TBI; in contrast, this therapy required the target blood glucose range to direct the dosage of insulin [22]. Unlike other brain diseases, such as ischemic stroke and intracerebral hemorrhage, the target blood glucose range for TBI has not been well documented. Although $6.0-10.0 \mathrm{mmol} / \mathrm{L}$ was predicted as the appropriate target range of blood glucose [1,22], this range was not fully substantiated by clinical research. In a previous study, based on the effect of IIT on 3and 6-month survival and GOS, we introduced that the blood glucose between 7.1 and $13.0 \mathrm{mmol} / \mathrm{L}$ would be the suitable target range for controlling hyperglycemia with insulin therapy following TBI. In the present study, we tried to confirm and further narrow the target blood glucose range in insulin therapy with advanced statistical tools.

During the secondary analysis of RCT with the multivariate regression analysis of the relationship between insulin therapy groups and 5-year and 6-month GOS, a possible ideal blood glucose range, 7.1$13 \mathrm{mmol} / \mathrm{L}$, was supplied, which had a positive effect on the outcomes. As support evidence for the aforementioned analysis, a "bell"-shaped relationship between the average blood glucose level in 7 days in insulin therapy and GOS was found, which was consistent with previous recognition that a too low or too high blood glucose level was harmful to the outcomes of patients [13, 14]. With the assistance of curve-fitting example and threshold effects analysis, we identified two inflection points in the aforementioned curves, following which the blood glucose was segregated into three ranges: low-level, medium-level, and high-level. The multivariate analysis revealed that the 5-year GOS was higher in the medium-level group than in the low-level and high-level groups. The blood glucose range in the mediumlevel group was $6.73-8.97 \mathrm{mmol} / \mathrm{L}$, which was consistent with the blood glucose range reported in a previous RCT and narrower than that previously reported. When using 6-month GOS as the outcome to identify the inflection points, the values of 6.95 and $8.88 \mathrm{mmol} / \mathrm{L}$ were achieved. Considering that more positive incidences were involved in 5-year GOS, we adopted $6.73-8.97 \mathrm{mmol} / \mathrm{L}$ as the recommended mean blood glucose range for insulin therapy. To quantify the effect of blood glucose level in insulin therapy on GOS, the multivariate analysis was performed between average blood glucose level and 5-year GOS. The result showed that controlling the blood glucose level in the range of $6.73-8.97 \mathrm{mmol} / \mathrm{L}$ (medium-level) could increase the 5 -year GOS by 0.84 and 0.55 when compared with the low-level group and the high-level group, respectively. This meant that patients could greatly benefit from proper blood glucose control in insulin therapy considering a few GOS changes, indicating a big improvement in prognosis [23]. 
Due to the influence of inclusion criteria, our study had some limitations. We selected critical patients with a GCS score of 3-8 and excluded patients with a GCS score of $>8$. Also, patients with bilateral mydriasis were excluded because of their high mortality. We excluded nonsurgical patients due to some interference differences between surgical and nonsurgical patients. The data used in this study were derived from an RCT that just involved a subset population of patients with TBI. Hence, the conclusion was suitable for a similar subset population. A cohort of patients with TBI of different severity may be a better choice to produce a target blood glucose range in future studies. Besides the aforementioned choice bias, multicenter studies with larger sample size would help achieve a more general conclusion about the target glucose range in insulin therapy.

In conclusion, proper blood glucose range in insulin therapy would improve outcomes of patients with $\mathrm{TBI}$; the range was $6.73-8.97 \mathrm{mmol} / \mathrm{L}$ according to our limited analysis.

\section{Declarations}

\section{Author details}

${ }^{1}$ Department of Neurosurgery, the affiliated Lianyungang Oriental Hospital of Xuzhou Medical University, 222042, Jiangsu Province, China. ${ }^{2}$ Center for clinical research and translational medicine, the affiliated Lianyungang Oriental Hospital of Xuzhou Medical University, 222042, Jiangsu Province, China. ${ }^{3}$ Department of Neurosurgery, the First People's Hospital of Lianyungang, Lianyungang, 222042, Jiangsu Province, China.

\section{Authorship}

T.Y. and H.H. were co-first authors who had contributed in data collection, data analysis, and article writing. W.W. was responsible for facilitating all aspects of this project including the study design, data analysis, data interpretation, drafting of the manuscript, and editing of the manuscript based on feedback from the coauthors. Y.L. was the primary statistician responsible for the data analysis. The remaining members of the writing group listed contributed to the data interpretation and provided critical review and revisions to the manuscript. All authors made substantial contributions to the acquisition of data.

\section{Conflicts of Interest and Source of Funding}

This study was supported by a grant (H201462) from GENERAL PROJECTS for the Department of Public Health of Jiangsu Province, China. Author Wenxue Wang is on the speaker's bureau for This study. For the remaining authors, no conflicts were declared.

\section{Acknowledgments:}

The authors are grateful to Dr. Xinglin Chen of the Department of Epidemiology and Biostatistics, X\&Y solutions Inc. in Boston for help with statistical analysis. 
Conflicts of Interest and Source of Funding:

This study was supported by a grant (H201462) from GENERAL PROJECTS for the Department of Public Health of Jiangsu Province, China. Author Wenxue Wang is on the speaker's bureau for This study. For the remaining authors, no conflicts were declared.

Appendix A. Supplementary data:

Supplementary data to this article can be found online at https://doi.org/10.5061/dryad.tx95x69xn

\section{References}

1. Matovu P, Kirya M, Galukande M, Kiryabwire J, Mukisa J, Ocen W, Lowery Wilson M, Abio A, Lule $\mathrm{H}$ : Hyperglycemia in severe traumatic brain injury patients and its association with thirty-day mortality: a prospective observational cohort study in Uganda. PeerJ 2021, 9:e10589.

2. Hermanides J, Plummer MP, Finnis M, Deane AM, Coles JP, Menon DK: Glycaemic control targets after traumatic brain injury: a systematic review and meta-analysis. Crit Care 2018, 22(1):11.

3. Moro N, Ghavim S, Harris NG, Hovda DA, Sutton RL: Glucose administration after traumatic brain injury improves cerebral metabolism and reduces secondary neuronal injury. Brain Res 2013, 1535:124-136.

4. Liu-DeRyke X, Collingridge DS, Orme J, Roller D, Zurasky J, Rhoney DH: Clinical impact of early hyperglycemia during acute phase of traumatic brain injury. Neurocrit Care 2009, 11(2):151-157.

5. Shijo K, Ghavim S, Harris NG, Hovda DA, Sutton RL: Glucose administration after traumatic brain injury exerts some benefits and no adverse effects on behavioral and histological outcomes. Brain Res 2015, 1614:94-104.

6. Jeremitsky E, Omert LA, Dunham CM, Wilberger J, Rodriguez A: The impact of hyperglycemia on patients with severe brain injury. $J$ Trauma 2005, 58(1):47-50.

7. Zhao QJ, Zhang XG, Wang LX: Mild hypothermia therapy reduces blood glucose and lactate and improves neurologic outcomes in patients with severe traumatic brain injury. J Crit Care 2011, 26(3):311315.

8. Pakhetra R, Garg MK, Suryanarayana KM: Management of Hyperglycemia in Critical Illness: Review of Targets and Strategies. Med J Armed Forces India 2011, 67(1):53-57.

9. Yang SY, Zhang S, Wang ML: Clinical significance of admission hyperglycemia and factors related to it in patients with acute severe head injury. Surg Neurol 1995, 44(4):373-377. 
10. Azevedo JR, Lima ER, Cossetti RJ, Azevedo RP: Intensive insulin therapy versus conventional glycemic control in patients with acute neurological injury: a prospective controlled trial. Arquivos de neuro-psiquiatria 2007, 65(3B):733-738.

11. Oddo M, Schmidt JM, Mayer SA, Chiolero RL: Glucose control after severe brain injury. Curr Opin Clin Nutr Metab Care 2008, 11(2):134-139.

12. Oddo M, Schmidt JM, Carrera E, Badjatia N, Connolly ES, Presciutti M, Ostapkovich ND, Levine JM, Le Roux P, Mayer SA: Impact of tight glycemic control on cerebral glucose metabolism after severe brain injury: a microdialysis study. Critical care medicine 2008, 36(12):3233-3238.

13. Godoy DA, Di Napoli M, Rabinstein AA: Treating hyperglycemia in neurocritical patients: benefits and perils. Neurocrit Care 2010, 13(3):425-438.

14. Graffagnino C, Gurram AR, Kolls B, Olson DM: Intensive insulin therapy in the neurocritical care setting is associated with poor clinical outcomes. Neurocrit Care 2010, 13(3):307-312.

15. American Diabetes A: 2. Classification and Diagnosis of Diabetes: Standards of Medical Care in Diabetes-2020. Diabetes Care 2020, 43(Suppl 1):S14-S31.

16. Carney N, Totten AM, O'Reilly C, Ullman JS, Hawryluk GW, Bell MJ, Bratton SL, Chesnut R, Harris $\mathrm{OA}$, Kissoon N et al: Guidelines for the Management of Severe Traumatic Brain Injury, Fourth Edition. Neurosurgery 2017, 80(1):6-15.

17. De Block CEM, Rogiers P, Jorens PG, Schepens T, Scuffi C, Van Gaal LF: A comparison of two insulin infusion protocols in the medical intensive care unit by continuous glucose monitoring. Ann Intensive Care 2016, 6(1):115.

18. Potapov AA, Krylov VV, Gavrilov AG, Kravchuk AD, Likhterman LB, Petrikov SS, Talypov AE, Zakharova NE, Solodov AA: [Guidelines for the management of severe traumatic brain injury. Part 3. Surgical management of severe traumatic brain injury (Options)]. Zh Vopr Neirokhir Im N N Burdenko 2016, 80(2):93-101.

19. Jaddoe VW, de Jonge LL, Hofman A, Franco OH, Steegers EA, Gaillard R: First trimester fetal growth restriction and cardiovascular risk factors in school age children: population based cohort study. BMJ 2014, 348:g14.

20. $\mathrm{Yu} \mathrm{X,} \mathrm{Cao} \mathrm{L,} \mathrm{Yu} \mathrm{X:} \mathrm{Elevated} \mathrm{cord} \mathrm{serum} \mathrm{manganese} \mathrm{level} \mathrm{is} \mathrm{associated} \mathrm{with} \mathrm{a} \mathrm{neonatal} \mathrm{high}$ ponderal index. Environ Res 2013, 121:79-83.

21. Yu X, Chen J, Li Y, Liu H, Hou C, Zeng Q, Cui Y, Zhao L, Li P, Zhou Z et al: Threshold effects of moderately excessive fluoride exposure on children's health: A potential association between dental fluorosis and loss of excellent intelligence. Environ Int 2018, 118:116-124. 
22. Baker L, Maley JH, Arevalo A, DeMichele F, 3rd, Mateo-Collado R, Finkelstein S, Celi LA: Realworld characterization of blood glucose control and insulin use in the intensive care unit. Sci Rep 2020, 10(1):10718.

23. Zhu C, Chen J, Pan J, Qiu Z, Xu T: Therapeutic effect of intensive glycemic control therapy in patients with traumatic brain injury: A systematic review and meta-analysis of randomized controlled trials. Medicine (Baltimore) 2018, 97(30):e11671.

\section{Tables}

Table 1. Baseline Characteristics of participants

\begin{tabular}{|c|c|c|c|c|c|c|}
\hline Group in $\mathrm{RCT}$ & Strict & Slight & Moderate & $\begin{array}{c}\text { Non- } \\
\text { intensive }\end{array}$ & Total & $\begin{array}{c}\mathrm{P}- \\
\text { value }\end{array}$ \\
\hline $\mathrm{N}$ & 45 & 45 & 46 & 46 & 182 & \\
\hline Age (years), Median (Q1-Q3) & $\begin{array}{c}50.00 \\
(33.00- \\
63.00)\end{array}$ & $\begin{array}{c}52.00 \\
(40.00- \\
61.00)\end{array}$ & $\begin{array}{c}50.00 \\
(31.00- \\
57.25)\end{array}$ & $\begin{array}{c}45.50 \\
(34.00- \\
56.00)\end{array}$ & $\begin{array}{c}50.00 \\
(34.00- \\
59.00)\end{array}$ & 0.266 \\
\hline Sex, n (\%) & & & & & & 0.647 \\
\hline male & $\begin{array}{c}35 \\
(77.78 \%)\end{array}$ & $\begin{array}{c}35 \\
(77.78 \%)\end{array}$ & $\begin{array}{c}37 \\
(80.43 \%)\end{array}$ & $\begin{array}{c}40 \\
(86.96 \%)\end{array}$ & $\begin{array}{c}147 \\
(80.77 \%)\end{array}$ & \\
\hline female & $\begin{array}{c}10 \\
(22.22 \%)\end{array}$ & $\begin{array}{c}10 \\
(22.22 \%)\end{array}$ & $9(19.57 \%)$ & $6(13.04 \%)$ & $\begin{array}{c}35 \\
(19.23 \%)\end{array}$ & \\
\hline Pupil changes, n (\%) & & & & & & 0.031 \\
\hline No & $\begin{array}{c}14 \\
(31.11 \%)\end{array}$ & $\begin{array}{c}25 \\
(55.56 \%)\end{array}$ & $\begin{array}{c}13 \\
(28.26 \%)\end{array}$ & $\begin{array}{c}16 \\
(34.78 \%)\end{array}$ & $\begin{array}{c}68 \\
(37.36 \%)\end{array}$ & \\
\hline Yes & $\begin{array}{c}31 \\
(68.89 \%)\end{array}$ & $\begin{array}{c}20 \\
(44.44 \%)\end{array}$ & $\begin{array}{c}33 \\
(71.74 \%)\end{array}$ & $\begin{array}{c}30 \\
(65.22 \%)\end{array}$ & $\begin{array}{c}114 \\
(62.64 \%)\end{array}$ & \\
\hline $\begin{array}{l}\text { GCS score before surgery, } \\
\text { Mean (SD) }\end{array}$ & $5.49(1.80)$ & $5.64(1.35)$ & $5.48(1.43)$ & $5.22(1.43)$ & $5.46(1.51)$ & 0.599 \\
\hline $\begin{array}{l}\text { APCHE II score before } \\
\text { surgery, Mean (SD) }\end{array}$ & $\begin{array}{l}29.00 \\
(2.89)\end{array}$ & $\begin{array}{r}28.47 \\
(1.87)\end{array}$ & $\begin{array}{r}28.39 \\
(1.87)\end{array}$ & $\begin{array}{l}29.04 \\
(2.77)\end{array}$ & $\begin{array}{l}28.73 \\
(2.40)\end{array}$ & 0.423 \\
\hline $\begin{array}{l}\text { Blood glucose before surgery } \\
(\mathrm{mmol} / \mathrm{L}) \text {, Mean (SD) }\end{array}$ & $\begin{array}{l}19.06 \\
(2.13)\end{array}$ & $\begin{array}{r}18.93 \\
(2.20)\end{array}$ & $\begin{array}{l}19.13 \\
(2.20)\end{array}$ & $\begin{array}{l}19.20 \\
(2.50)\end{array}$ & $\begin{array}{l}19.08 \\
(2.25)\end{array}$ & 0.948 \\
\hline $\begin{array}{l}\text { GHb before surgery, \%, Mean } \\
\text { (SD) }\end{array}$ & $5.87(1.12)$ & $5.85(0.88)$ & $5.72(0.97)$ & $5.90(0.87)$ & $5.83(0.96)$ & 0.832 \\
\hline $\begin{array}{l}\text { CSF glucose during surgery } \\
(\mathrm{mmol} / \mathrm{L}) \text {, Mean (SD) }\end{array}$ & $5.19(0.67)$ & $5.20(0.97)$ & $5.42(0.71)$ & $5.22(0.88)$ & $5.26(0.81)$ & 0.477 \\
\hline $\begin{array}{l}\text { CSF LA during surgery } \\
(\mathrm{mmol} / \mathrm{L}) \text {, Mean (SD) }\end{array}$ & $4.08(0.78)$ & $4.07(0.61)$ & $3.98(0.68)$ & $4.10(0.60)$ & $4.06(0.67)$ & 0.829 \\
\hline $\begin{array}{l}\text { Average blood glucose level } \\
\text { (mmol/L), Mean (SD) }\end{array}$ & $\begin{array}{c}6.01 \\
(0.82)\end{array}$ & $7.63(0.86)$ & $\begin{array}{l}10.03 \\
(1.01)\end{array}$ & $\begin{array}{l}12.44 \\
(1.61)\end{array}$ & $9.05(2.68)$ & $<0.001$ \\
\hline
\end{tabular}

GCS, Glasgow coma score; APCHE II, Acute Physiology and Chronic Health Evaluation II; GHb, Glycosylated hemoglobin; CSF, Cerebrospinal fluid; LA, Lactic Acid. 
Table 2. Outcome of participants

\begin{tabular}{|c|c|c|c|c|c|c|}
\hline Group in $\mathrm{RCT}$ & Strict & Slight & Moderate & $\begin{array}{c}\text { Non- } \\
\text { intensive }\end{array}$ & Total & $\begin{array}{c}\mathrm{P}- \\
\text { value }\end{array}$ \\
\hline $\begin{array}{l}\text { 6-month Glasgow Outcome Score, } \\
\text { Median(Q1-Q3) }\end{array}$ & $\begin{array}{l}3.00(1.00- \\
4.00)\end{array}$ & $\begin{array}{l}4.00(3.00- \\
5.00)\end{array}$ & $\begin{array}{l}4.00(3.00- \\
5.00)\end{array}$ & $\begin{array}{l}3.00(2.00- \\
3.00)\end{array}$ & $\begin{array}{l}3.00(2.00- \\
4.00)\end{array}$ & 0.001 \\
\hline$=1 \square$ Death $\square$ & $\begin{array}{c}12 \\
(26.67 \%)\end{array}$ & $4(8.89 \%)$ & $6(13.04 \%)$ & $\begin{array}{c}11 \\
(23.91 \%)\end{array}$ & $\begin{array}{c}33 \\
(18.13 \%)\end{array}$ & \\
\hline$=2,3$ & $\begin{array}{c}17 \\
(37.78 \%)\end{array}$ & $\begin{array}{c}15 \\
(33.33 \%)\end{array}$ & $\begin{array}{c}12 \\
(26.09 \%)\end{array}$ & $\begin{array}{c}25 \\
(54.35 \%)\end{array}$ & $\begin{array}{c}69 \\
(37.91 \%)\end{array}$ & \\
\hline$=4,5$ & $\begin{array}{c}16 \\
(35.56 \%)\end{array}$ & $\begin{array}{c}26 \\
(57.78 \%)\end{array}$ & $\begin{array}{c}28 \\
(60.87 \%)\end{array}$ & $\begin{array}{c}10 \\
(21.74 \%)\end{array}$ & $\begin{array}{c}80 \\
(43.96 \%)\end{array}$ & \\
\hline $\begin{array}{l}\text { 5-year Glasgow Outcome Score, } \\
\text { Median(Q1-Q3) }\end{array}$ & $\begin{array}{l}3.00(1.00- \\
\quad 4.00)\end{array}$ & $\begin{array}{l}4.00(3.00- \\
5.00)\end{array}$ & $\begin{array}{l}4.00(4.00- \\
5.00)\end{array}$ & $\begin{array}{l}3.00(1.00- \\
3.00)\end{array}$ & $\begin{array}{l}4.00(1.00- \\
\quad 4.00)\end{array}$ & $<0.001$ \\
\hline$=1 \square$ Death $\square$ & $\begin{array}{c}18 \\
(40.00 \%)\end{array}$ & $\begin{array}{c}7 \\
\text { (15.56\%) }\end{array}$ & $9(19.57 \%)$ & $\begin{array}{c}18 \\
(39.13 \%)\end{array}$ & $\begin{array}{c}52 \\
(28.57 \%)\end{array}$ & \\
\hline$=2,3$ & $\begin{array}{c}12 \\
(26.67 \%)\end{array}$ & $\begin{array}{l}5 \\
(11.11 \%)\end{array}$ & $1(2.17 \%)$ & $\begin{array}{c}17 \\
(36.96 \%)\end{array}$ & $\begin{array}{c}35 \\
(19.23 \%)\end{array}$ & \\
\hline$=4,5$ & $\begin{array}{c}15 \\
(33.33 \%)\end{array}$ & $\begin{array}{c}33 \\
(73.33 \%)\end{array}$ & $\begin{array}{c}36 \\
(78.26 \%)\end{array}$ & $\begin{array}{c}11 \\
(23.91 \%)\end{array}$ & $\begin{array}{c}95 \\
(52.20 \%) \\
\end{array}$ & \\
\hline
\end{tabular}




\begin{tabular}{|c|c|c|c|}
\hline & Statistics & 6-month & 5-year \\
\hline & & OR (95\%CI) P-value & OR (95\%CI) P-value \\
\hline \multicolumn{4}{|l|}{ Study Group, n(\%) } \\
\hline Non-intensive & $46(25.27 \%)$ & Reference & Reference \\
\hline Strict & $45(24.73 \%)$ & $\begin{array}{l}0.21(-0.30,0.73) \\
0.4213\end{array}$ & $\begin{array}{l}0.23(-0.34,0.80) \\
0.4292\end{array}$ \\
\hline Moderate & $45(24.73 \%)$ & $\begin{aligned} 1.17 & (0.65,1.69) \\
& <0.0001\end{aligned}$ & $\begin{array}{c}1.45(0.88,2.02) \\
<0.0001\end{array}$ \\
\hline Slight & $46(25.27 \%)$ & $\begin{array}{c}1.13(0.62,1.64) \\
<0.0001\end{array}$ & $\begin{array}{c}1.39(0.82,1.96) \\
<0.0001\end{array}$ \\
\hline \multicolumn{4}{|l|}{ Sex, $n(\%)$} \\
\hline male & $\begin{array}{c}147 \\
(80.77 \%)\end{array}$ & Reference & Reference \\
\hline female & $35(19.23 \%)$ & $\begin{array}{c}-0.17(-0.67,0.33) \\
0.5129\end{array}$ & $\begin{array}{c}-0.13(-0.70,0.43) \\
0.6402\end{array}$ \\
\hline Age, year & $\begin{array}{c}46.73 \pm \\
16.29\end{array}$ & $\begin{array}{l}0.00(-0.01,0.01) \\
0.6641\end{array}$ & $\begin{aligned}-0.00 & (-0.01,0.01) \\
& 0.9376\end{aligned}$ \\
\hline \multicolumn{4}{|l|}{ Pupil changes, n(\%) } \\
\hline no & $68(37.36 \%)$ & Reference & Reference \\
\hline yes & $\begin{array}{c}114 \\
(62.64 \%)\end{array}$ & $\begin{array}{c}-0.73(-1.12,-0.33) \\
0.0004\end{array}$ & $\begin{array}{l}-0.72(-1.17,-0.27) \\
0.0019\end{array}$ \\
\hline GCS score before surgery, mean \pm SD & $5.46 \pm 1.51$ & $0.20(0.07,0.33) 0.0023$ & $\begin{array}{c}0.20(0.05,0.34) \\
0.0088\end{array}$ \\
\hline APCHE II score before surgery, mean \pm SD & $28.73 \pm 2.40$ & $\begin{aligned}-0.18 & (-0.25,-0.10) \\
& <0.0001\end{aligned}$ & $\begin{array}{l}-0.18(-0.27,-0.09) \\
0.0001\end{array}$ \\
\hline $\begin{array}{l}\text { Blood GLU before surgery, } \mathrm{mmol} / \mathrm{L} \text {, } \\
\text { mean } \pm \mathrm{SD}\end{array}$ & $19.08 \pm 2.25$ & $\begin{array}{c}-0.13(-0.22,-0.04) \\
0.0037\end{array}$ & $\begin{array}{l}-0.11(-0.21,-0.01) \\
0.0256\end{array}$ \\
\hline GHb before surgery, $\%$, mean \pm SD & $5.83 \pm 0.96$ & $\begin{array}{c}-0.26(-0.46,-0.05) \\
0.0142\end{array}$ & $\begin{array}{c}-0.20(-0.43,0.03) \\
0.0977\end{array}$ \\
\hline $\begin{array}{l}\text { CSF GLU during surgery, } \mathrm{mmol} / \mathrm{L} \text {, } \\
\text { mean } \pm \text { SD }\end{array}$ & $5.26 \pm 0.81$ & $0.33(0.09,0.57) 0.0080$ & $\begin{array}{c}0.26(-0.02,0.53) \\
0.0671\end{array}$ \\
\hline CSF LA during surgery, $\mathrm{mmol} / \mathrm{L}$, mean $\pm \mathrm{SD}$ & $4.06 \pm 0.67$ & $\begin{array}{l}-0.37(-0.66,-0.08) \\
0.0141\end{array}$ & $\begin{array}{l}-0.28(-0.61,0.05) \\
0.0969\end{array}$ \\
\hline $\begin{array}{l}\text { Average blood glucose level, } \mathrm{mmol} / \mathrm{L} \text {, } \\
\text { mean } \pm \text { SD }\end{array}$ & $9.05 \pm 2.68$ & $\begin{array}{c}-0.09(-0.16,-0.02) \\
0.0144\end{array}$ & $\begin{array}{c}-0.09(-0.17,-0.01) \\
0.0334\end{array}$ \\
\hline $\begin{array}{l}\text { Total insulin consumption in } 7 \text { days, } \mathrm{U} \text {, } \\
\text { mean } \pm \text { SD }\end{array}$ & $\begin{array}{c}207.86 \pm \\
66.94\end{array}$ & $\begin{array}{l}0.00(-0.00,0.00) \\
0.7164\end{array}$ & $\begin{array}{c}-0.00(-0.00,0.00) \\
0.8822\end{array}$ \\
\hline
\end{tabular}

Abbreviations: CI, confidence interval. OR, odds ratio. GCS, Glasgow coma score. APCHE II, Acute Physiology and Chronic Health Evaluation II. BI, Barthel Index. GOS, Glasgow Outcome Score. GHb, Glycosylated hemoglobin. CSF, Cerebrospinal fluid. Glu, Glucose; LA, Lactic Acid, BI, Barthel Index. 
Table 4. Relationship between Group in RCT and Glasgow Outcome Score in 6-month and 5-year

\begin{tabular}{|c|c|c|}
\hline \multirow{2}{*}{\multicolumn{2}{|c|}{ Exposure }} & Adjust model \\
\hline & & $\beta$ (95\%CI) P-value \\
\hline \multicolumn{3}{|c|}{ 6-month Glasgow Outcome Score } \\
\hline \multicolumn{3}{|c|}{ Study Group } \\
\hline Non-intensive & & Reference \\
\hline Strict & & $0.27(-0.26,0.80) 0.3163$ \\
\hline Slight & & $0.94(0.41,1.47) 0.0007$ \\
\hline Moderate & & $1.01(0.49,1.52) 0.0002$ \\
\hline \multicolumn{3}{|l|}{ 5-year Glasgow Outcome Score } \\
\hline \multicolumn{3}{|c|}{ Study Group } \\
\hline Non-intensive & & Reference \\
\hline Strict & & $0.28(-0.31,0.87) 0.3498$ \\
\hline Slight & & $1.15(0.56,1.74) 0.0002$ \\
\hline Moderate & & $1.26(0.69,1.84)<0.0001$ \\
\hline \multicolumn{3}{|c|}{$\begin{array}{l}\text { Adjust model adjust for: Pupil changes; Glasgow coma score before surgery; Acute Physiology and Chronic } \\
\text { Health Evaluation II before surgery. }\end{array}$} \\
\hline \multicolumn{3}{|c|}{$\begin{array}{l}\text { Table 5. Threshold Effect Analysis of Average blood glucose (mmol/L) with Glasgow } \\
\text { coma score in 6-month and 5-year using Piece-wise Linear Regression }\end{array}$} \\
\hline \multirow[t]{2}{*}{ Outcome } & 6-month Glasgow coma score & 5-year Glasgow coma score \\
\hline & $\beta$ (95\%CI) P-value & $\beta(95 \%$ CI $)$ P-value \\
\hline \multicolumn{3}{|l|}{ Model I } \\
\hline A linear Inflection & $-0.09(-0.16,-0.02) 0.0144$ & $-0.10(-0.18,-0.02) 0.0185$ \\
\hline \multicolumn{3}{|l|}{ Model II } \\
\hline Inflection point $(\mathrm{K} 1, \mathrm{~K} 2)$ & $\mathrm{K} 1=6.95, \mathrm{~K} 2=8.88$ & $\mathrm{~K} 1=6.73, \mathrm{~K} 2=8.97$ \\
\hline$<\mathrm{K} 1$ & $0.68(0.24,1.13) 0.0032$ & $0.71(0.13,1.29) 0.0171$ \\
\hline $\mathrm{K} 1-\mathrm{K} 2$ & $-0.17(-0.75,0.41) 0.5653$ & $0.06(-0.48,0.61) 0.8170$ \\
\hline$>\mathrm{K} 2$ & $-0.38(-0.52,-0.23)<0.0001$ & $-0.41(-0.57,-0.25)<0.0001$ \\
\hline Log Likelihood Ratio Tests & $<0.001$ & $<0.001$ \\
\hline
\end{tabular}


Table 6. Relationship between Average blood glucose level (mmol/L) and 5-year Glasgow coma score.

\begin{tabular}{|c|c|c|c|}
\hline \multirow[t]{2}{*}{ Statistics } & \multirow[t]{2}{*}{$\mathrm{n}(\%)$} & Non-adjusted & Adjust model \\
\hline & & $\beta$ (95\%CI) P-value & $\beta$ (95\%CI) P-value \\
\hline \multicolumn{4}{|l|}{$\begin{array}{l}\text { Average Blood glucose level } \\
(\mathrm{mmol} / \mathrm{L})\end{array}$} \\
\hline$<6.73$ & $\begin{array}{c}42 \\
(23.08 \%)\end{array}$ & Reference & Reference \\
\hline$>=6.73,<8.97$ & $\begin{array}{c}47 \\
(25.82 \%)\end{array}$ & $0.99(0.37,1.61) 0.0021$ & $0.83(0.22,1.43) 0.0084$ \\
\hline$>=8.97$ & $\begin{array}{c}93 \\
(51.10 \%)\end{array}$ & $0.33(-0.21,0.87) 0.2374$ & $0.26(-0.27,0.78) 0.3389$ \\
\hline \multicolumn{4}{|l|}{$\begin{array}{l}\text { Average Blood glucose level } \\
(\mathrm{mmol} / \mathrm{L})\end{array}$} \\
\hline$>=8.97$ & $\begin{array}{c}93 \\
(51.10 \%)\end{array}$ & Reference & Reference \\
\hline$>=6.73,<8.97$ & $\begin{array}{c}47 \\
(25.82 \%)\end{array}$ & $0.66(0.14,1.18) 0.0145$ & $0.57(0.05,1.08) 0.0314$ \\
\hline$<6.73$ & $\begin{array}{c}42 \\
(23.08 \%)\end{array}$ & $\begin{array}{c}-0.33(-0.87,0.21) \\
0.2374\end{array}$ & $-0.26(-0.78,0.27) 0.3389$ \\
\hline
\end{tabular}

Adjust model adjust for: Pupil changes; Glasgow coma score before surgery; Acute Physiology and Chronic Health Evaluation II.

\section{Figures}




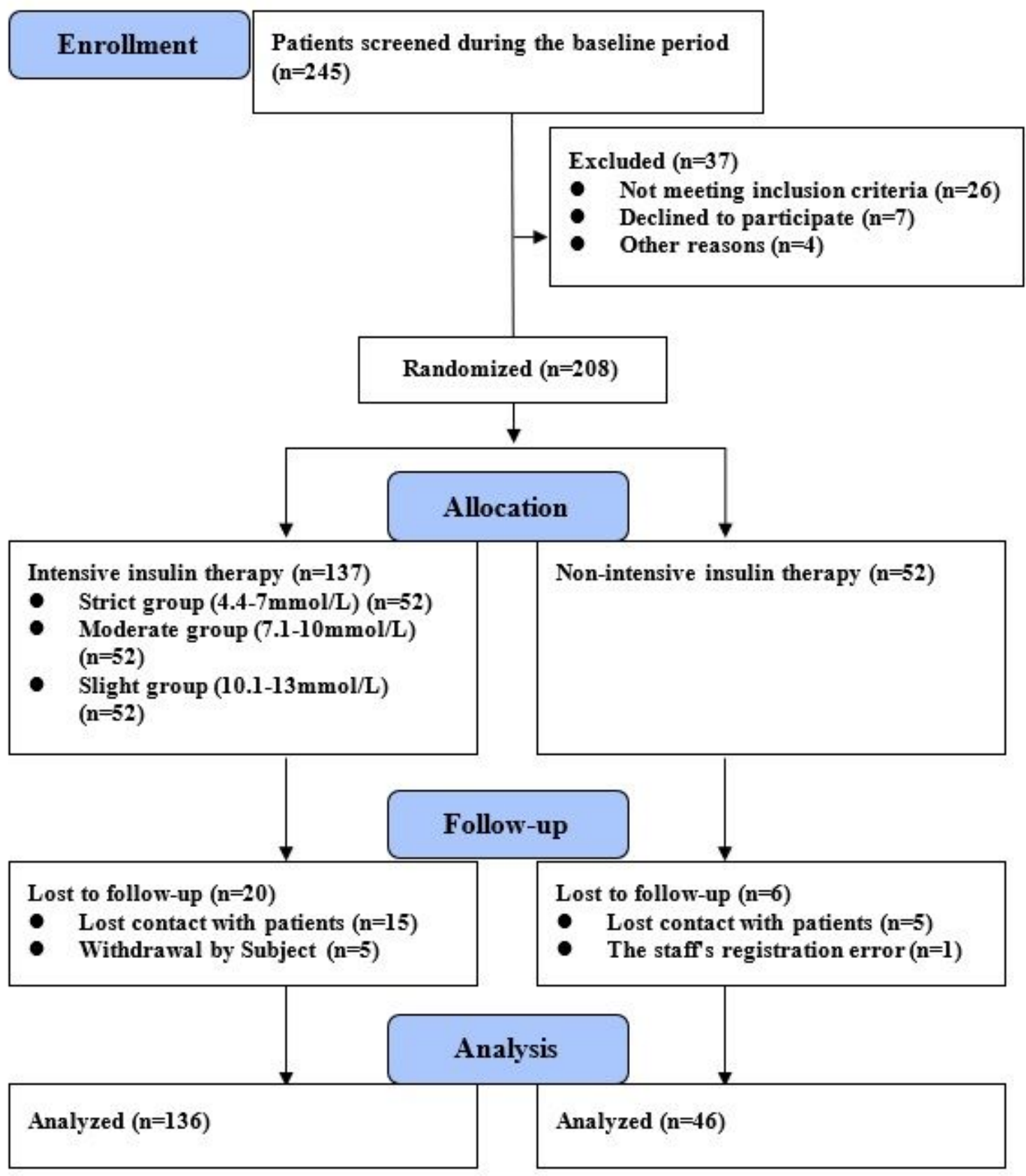

Figure 1

CONSORT 2010 Transparent Reporting of Trials: Flow diagram. 

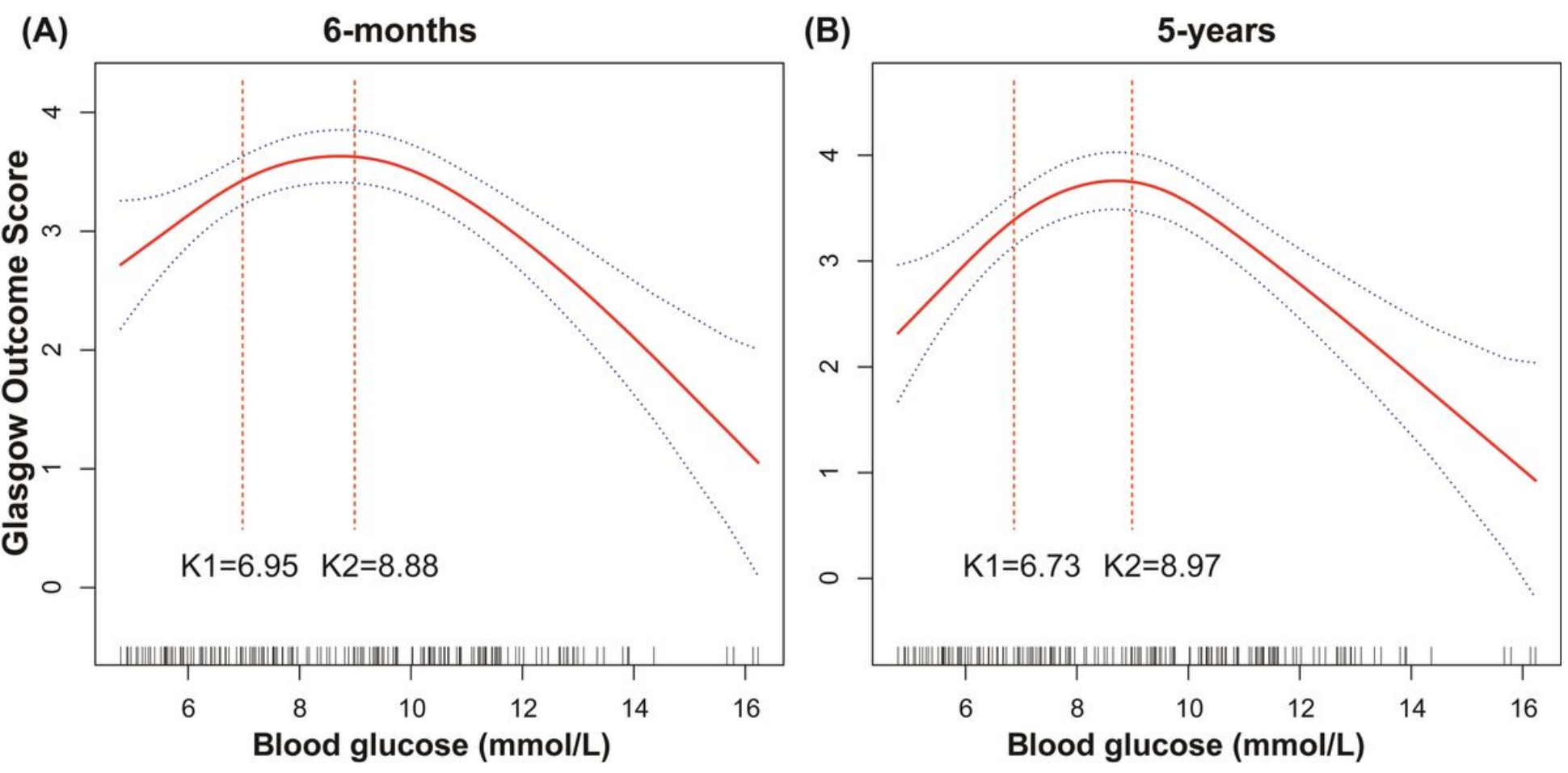

Figure 2

(A) A threshold, nonlinear association between the average blood glucose level ( $\mathrm{mmol} / \mathrm{L}$ ) and 6-month GOS was found in a generalized additive model (GAM). Solid red line represents the smooth curve fit between variables. Blue bands represent the $95 \%$ confidence interval from the fit; 6.95 and $8.88 \mathrm{mmol} / \mathrm{L}$ (blood glucose level) were its inflection points (K1 and K2). (B) Average blood glucose level ( $\mathrm{mmol} / \mathrm{L}$ ) versus 5-year GOS, in which 6.73 and $8.97 \mathrm{mmol} / \mathrm{L}$ (average blood glucose level) were identified as the inflection points ( $\mathrm{K} 1$ and $\mathrm{K} 2$ ).

\section{Supplementary Files}

This is a list of supplementary files associated with this preprint. Click to download.

- CONSORT2010Checklist.doc 